\title{
LOS DELITOS CULPOSOS
}




\section{RUIZ RAMAL, Ariana $^{76}$}

Sumario: 1. Introducción. - 2. Teoría del delito. - 3. Delitos culposos. -4 . La punibilidad. - 5. La culpa. - 6. Imprudencia. 7. Negligencia. - 8. Impericia. 9. Tipo Objetivo. - 10. El deber de cuidado. - 11. El resultado. - 12. Tipo subjetivo. - 13. Fundamentación de la culpa. - 14. Conclusiones.

\section{Introducción}

En los delitos culposos hay que distinguir cuidadosamente el conocimiento efectivo o potencial del peligro que la conducta crea para los bienes jurídicos, del conocimiento abstracto del deber de cuidado. El conocimiento del peligro causado es efectivo en la culpa consciente o con representación, pero es potencial en la culpa inconsciente o sin representación. Cuando ese conocimiento falta en forma efectiva y no es exigible, faltará la tipicidad culposa, pero cuando no es ese el caso, sino que el sujeto desconoce directamente su deber de cuidado en forma abstracta, no puede pretenderse que reconozca la anti juridicidad concreta de su conducta y reprochársele por no haberla conocido, pese a que conozca perfectamente el peligro que con la misma introduce, lo que configurara un claro supuesto de error directo de prohibición ${ }^{77}$.

${ }^{76}$ Abogada por la USMP, Especialista en derecho penal.

${ }^{77}$ Ver: Zaffaroni, Tratado de Derecho Penal Parte General, Ediar, Argentina 1999, pp. 195-200. Donde señala: Los delitos culposos siempre fueron problemáticos, a1 punto de ponerse en duda la culpabilidad en ellos, cosa que jamás aconteció con los dolosos y ni siquiera con los omisivos. La característica esencial del tipo culposo y la diferencial respecto del doloso- es la forma de individualización de ,la conducta prohibida. En tanto que en el tipo doloso la conducta se ciñe, por lo general, mediante una descripción, en el tipo culposo ésta permanece prima facie indeterminada, siendo sólo determinable frente a cada caso concreto.

Cabe insistir una vez porque nunca será suficiente. dada la confusión creada2- en que el tipo culposo también individualiza conductas, que son tan "finales" como las individualizadas por los tipos dolosos'. Los tipos legales individualizan conductas y es imposible que individualicen otras cosas, porque es inconcebible que prohíban algo distinto de conductas humanas. Por consiguiente, el tipo culposo, al igual que el doloso, no puede hacer nada diferente que individualizar conductas humanas. Si la conducta no se concibe sin voluntad, y la voluntad no se concibe sin finalidad, la conducta que individualiza el tipo culposo tendrá una finalidad, igual que la que individualiza el tipo doloso. Todo este planteo parece una simpleza y, en verdad. lo es. Puede reducirse a lo siguiente: los tipos (dolosos y culposos) contienen prohibiciones de conductas. No obstante esta simplicidad, la aclaración se hace necesaria porque en razón de planteamientos idealistas, que conciben a lo prohibido como creado por !a norma que lo prohíbe, se ha confundido lo que se prohíbe con la forma en que se lo prohíbe.

El tipo culposo no individualiza la conducta por la finalidad, sino porque en la forma en que se ha querido obtener esa finalidad se ha violado un deber de cuidado. Pero la circunstancia 
En los delitos omisivos hay que distinguir el error que recae sobre la situación objetiva de la que se deriva la posición de garante (Padre, cónyuge, médico de guardia, etc.), cuyo desconocimiento dará lugar a un error de tipo, del desconocimiento del deber de cuidado que de esa posición se deriva, cuyo desconocimiento debe dar lugar al error de prohibición. Hay error de tipo cuando el médico no sabe que está de guardia, pero hay error de prohibición cuando ignora que estando de guardia tiene el deber de asistir sin excepciónalguna; hay error de tipo cuando el sujeto ignora que es el cónyuge, pero hay error de prohibición cuando ignora que su condición de cónyuge le impone velar por la integridad física del otro; etc.

\section{Teoría del Delito}

La Teoría General del delito se puede señalar como un conjunto de proposiciones sistemáticas organizadas que pretende explicar la naturaleza jurídica del hecho punible ${ }^{78}$.

de que el tipo no individualice la conducta por la finalidad en sí misma, no significa que no tenga finalidad, lo que parecen haber entendido numerosos autores.

El tipo es una figura que crea el legislador, una imagen que da a muy grandes trazos y al sólo efecto de permitir la individualización de algunas conductas. Cuando se toman algunos caracteres para individualizar un objeto cualquiera, como ser algunas características personales para individualizar a ciertas personas, como cuando se describen los hombres de raza amarilla por la forma de sus ojos, esto no significa que los hombres de raza amarilla no tengan nariz. El tipo culposo hace lo mismo: individualiza conductas porque en 12 forma de obtención de su finalidad violan un deber de cuidado, pero no porque no tengan finalidad.

${ }^{78}$ Villa Stein, Javier, Derecho Penal parte General, Grijley 2008, p. 171. La teoría del delito es, entonces, un constructor epistémico que facilita la definición conceptual y el análisis secuencial del delito como conducta humana compleja e inaceptablemente transgresora de la norma estatal prohibitiva o imperativa.

Desde luego, su carácter abstracto persigue, como toda teoría que se precise de tal, una finalidad práctica consistente en facilitar la determinación precisa del universo de conductas que son ciertas e inconfundiblemente contrarias al orden jurídico social, cuantificar la intensidad de la contrariedad y aplicar con enérgica prudencia la contingencia sancionadora que el Estado liberal y democrático de Derecho, tribunales de justicia mediante, considere oportuno y necesario conforme determinada racionalidad político criminal .

Las peculiaridades de cada evento criminal son materia de estudio de la parte especial del Derecho penal, llamado catálogo de delitos y penas. Sin embargo, todo esos eventos tienen propiedades comunes, siendo las primeras y demás evidentes de estas propiedades, ser conductas humanas y estar anticipadas en el aludido catálogo. De estas propiedades comunes da cuentas pues, como bien dice Muñoz Conde, la teoría del delito, cuerpo organizado y sistemático conocimiento que se comprende en la parte general del derecho penal, y sirva de instrumento a la interpretación y racionalidad jurídica..

En términos de Cabo de Rosal y Vives Antón, nace la teoría jurídica del delito como sede en la que se han formular las proposiciones generales que pretenden y debieran tener virtualidad para todas las hipótesis delictivas. Su naturaleza es, en consecuencia, abstracta y generalizadora. 
Se puede decir también que el Teoría General del delito como un cuerpo organizado y sistemático de conocimiento que se aprecia y comprende en la parte general del Derecho penal y sirva como instrumento y herramienta a la interpretación legal jurídica.

\subsection{Delito}

Es una acción u omisión típicamente antijurídica imputable al culpable y sancionado con una pena. También son delitos o faltas las acciones y omisiones dolosas o imprudentes penales por la ley ${ }^{79}$. Nuestro ordenamiento penal consagra, precisamente al hecho punible, nos dice que son delitos y faltas las acciones $\mathrm{u}$ omisiones dolosas $\mathrm{u}$ culposas penas por la Ley.

\section{Delitos Culposos}

La culpa se define tradicionalmente como la falta de previsión de un resultado; el mismo que puede cometer por imprudencia o negligencia en la conducta de la persona. ${ }^{80}$

La filosofía del Derecho es materia principal de la dogmática jurídica penal como disciplina que se ocupa de la interpretación, elaboración y desarrollo de las disposiciones legales y opiniones de la doctrina científica en el campo del Derecho penal.

${ }^{79}$ En términos generales, el delito es toda conducta que el legislador castiga con una pena. No obstante, parece dominante en la doctrina, la fijación del delito, desde una perspectiva más analítica, como "comportamiento antijurídico amenazado con pena y determinado en sus caracteres por el tipo de una Ley penal, que el autor ha realizado de modo culpable.

Es obvio que junto al delito, y en relación a las medidas de seguridad, se desarrollan los estados peligrosos, entendidos como la concreción, a partir de la realización de un delito y dentro de una determinando categoría de personas, de un pronóstico de comportamiento futuro que revele la probabilidad de comisión de nuevos hechos criminales, concebidos como complementos del delito, en cuanto a la necesaria comisión previa, su presencia conceptual es asimismo accesoria y dependiente de aquel.

80 Antonio Terragni, Marco, El Delito Culposo, Editorial Rubinzal -Culzoni - Chile, 3573, p.11. señala. La palabra culpa tiene múltiples significaciones, pues se designa desde la característica que hace un sujeto deba responder jurídicamente, con lo cual se la hace sinónimo de culpabilidad, hasta una de las formas del reproche, ocupando un lugar junto al dolo. Puede representar (en la moderna doctrina penal) una característica subjetiva del tipo, o también ser el elemento aglutinador de las formas que adopta un determinado obrar (imprudencia, negligencia, etc) lo que en algunos ordenamientos puede adquirir sustantividad en la forma del crimen culpae.

Las definiciones de culpa son numerosas, tantas como los intentos de caracterizarla y buscarla sinónimos. Sin embargo, llama la atención que pocas veces se vaya advirtiendo que resulta imposible señalar los contornos de la culpa en sí por que ésta no existe. Ni 
La culpa puede ser considerada como un componente psicomental vinculado al autor en el momento de la infracción delictiva, basando el reproche de la sociedad en la ausencia de un resultado querido y en el incumplimiento de los deberes de cuidado ${ }^{81}$.

Dentro de nuestro ordenamiento jurídico penal no establece una definición sobre la culpa, por lo que el Juez, al momento de Administrar la Justicia es el encargo de cerrar el concepto. La culpa entonces es un tipo abierto, ya que debe ser completado por la autoridad judicial; para que se pueda dar esta operación se debe analizar el deber objetivo de cuidado que debió tener el sujeto activo. ${ }^{82}$

conceptualmente ni tampoco gramaticalmente es correcta su sustantivización. En realidad se trata de una cualidad de la acción, por lo que es un adjetivo que le asigna un valor a ese fenómeno que él si tiene existencia autónoma.

${ }^{81}$ Ver Villavicencio Terreros, Felipe, Derecho Penal Parte General, Grijley, Lima 2007, pp. 381-384. Donde nos señala los ejemplos de delitos culposos: art 106, 111.

82 Hurtado Pozo, José, Manual del Derecho Penal, Parte General I, Editora Jurídica Grijley E.I.R.L. Perú. 3 Edición 2005, pp. 709,710, señala. El artículo 11 del Código penal, considera que los delitos y las faltas pueden estar constituidos por acciones u omisiones tanto dolosas como culposas. De esta manera, se consideran las formas tradicionales de infracciones penales: por un lado, las cometidas mediante la ejecución o la omisión de una acción y, por otro, desde una perspectiva subjetiva las realizaciones con dolo o culpa. Así, nuestro legislador no hace sino seguir las tradiciones del derecho penal de Europa continental. La importancia de los comportamientos culposos han aumentado de modo notable con los cambios substanciales producidos por la mecanización y la automatización de grandes sectores de las actividades domésticas, comerciales e industriales. Un ejemplo claro, es el del transporte, ámbito en el que los medios son cada vez mas veloces y tecnificados. Estos medios, sin duda, comportan grandes ventajas; pero, al mismo tiempo, son fuentes de riegos para las personas y el medio ambiente. Esta evolución ha hecho posible que las sociedades desarrolladas sean calificadas de sociedades de riesgo y que se les considere como ámbito propicio para la proliferación de diversos comportamientos imprudentes. Esto permite comprender que las infracciones culposas, según las estadísticas, constituye un gran porcentaje de los delitos cometidos y, por lo tanto, sean la materia de una buena parte de los procesos que ocupan a los órganos de control penal.

En la legislación, los tipos legales que prevén delitos culposos son una minoría en relación con los que reprimen delitos dolosos. La represión de éstos es prevista como la regla, mientras que la de los delitos imprudentes como excepcional. Las penas previstas para los responsables de los primeros son muchos menos graves que las estatuidas para los agentes del delito doloso. Las razones son, primero, que se estima innecesaria la protección de todos los bienes jurídicos contra los perjuicios causados mediante comportamientos culposos. Solo algunos de los bienes jurídicos más importantes (por ejemplo, la vida, la salud) son tenidos en cuenta. Cuando este es el caso, el legislador debe establecerlo mediante la elaboración de un tipo legal específico, haciendo constar de manera expresa que se reprime a título de culpa. Esto significa que conforme al artículo 12, rige en el derecho penal peruano el sistema de numerus clausus de delitos culposos, que presupone la regla general de que solo se reprime a título de dolo y, por el contrario, de manera excepcional a título de culpa. La segunda razón es que se les considera menor grave y que, en consecuencia, hay que tratarlo de manera desigual. Defiere tanto en la 


\section{La punibilidad}

En cuanto a los fundamentos de la punibilidad podemos señalar: $a$ ) el desvalor de la acción, por crear o incrementar el peligro o riesgo cuando se infringe una norma de cuidado. $b$ ) el desvalor del resultado, por poner en peligro o la lesión que se genera en contra del bien jurídico protegido.

\section{La culpa}

La culpa constituye una forma de culpabilidad, respecto al dolo, de adquisición más tardía, menos graves, es legislada excepcionalmente y de manera minoritaria y subsidiariamente (porque una responsabilidad culposa sería ilógica sin la previsión para el mismo hecho de una responsabilidad dolosa, en cuanto medio para una completa tutela de bienes jurídicos primarios ${ }^{83}$.

\subsection{Clases de culpa}

Existen dos clases de culpa:

a) Culpa consciente: cuando el sujeto si bien no quiere causar el resultado advierte la posibilidad que este ocurra pero confía en que no ocurrirá.

b) Culpa inconsciente: no sólo no se quiere el resultado lesivo, sino que ni siquiera se prevé su posibilidad: no se advierte el peligro.

La diferencia entre la culpa consciente y la inconsciente radica en la previsibilidad que puede tener el hombre medio: si prevé el resultado será culpa consiente; de lo contrario será inconsciente si el hecho no podía ser previsto; entonces no existe culpa; sino que el hecho es fortuito. Esta Primera parte se llama previsibilidad objetiva.

Nuestro Código Penal no hace diferencia entre las clases de culpa, pero esta diferencia es importante para diferenciar entre el dolo eventual y la culpa consciente en el

intensidad de la ilicitud como de la culpabilidad. Esto implica, por ejemplo, que la exclusión del carácter ilícito de la acción culposa sea admitida con mayor factibilidad que en caso de la acción dolosa y que la pena sea menos severas. Al respecto, basta comprar las penas previstas para el homicidio simple (pena privativa de libertad no menor de seis ni mayor de veinte años, art. 106) y para los homicidios culposos (pena privativa de libertad no mayor de dos años o prestación de servicio comunitario de cincuenta y dos a ciento cuatro jornadas, art. 111).

${ }^{83}$ Sobre la culpa ver: Mantovani, Ferrando, Diritto Penale, Cedam, Milano 2001, pp. 341-351. Sobre la culpa ver Jimenez DE AzuA, Tratado de Derecho Penal, T. V, Losada, Buenos Aires 1963, p. 677. Donde nos señala que la culpa, en su sentido más amplio y general, es la producción de un resultado típicamente antijurídico que pudo y debió ser previsto y que por negligencia o impericia del agente causa un efecto dañoso y que su evolución se originó en el Derecho Civil de Roma, bajo el concepto de la negligencia, imprudencia o impericia 
primero asumo el peligro, en la segunda confío en que el resultado no se produciría, además, el juzgador puede tomar estos criterios al momento de determinar la pena. ${ }^{84}$

\subsection{Manifestación de la culpa}

${ }^{84}$ Antonio Terragni, Marco, El Delito Culposo, Editorial Rubinzal -Culzoni - Chile, 3573, p.30,31-32, establece, consciente e inconsciente: estas clasificaciones están referidas al contenido de la conciencia respecto del hecho. Si el individuo se representó las posibles consecuencias de su acción y no obstante confió evitar los efectos dañosos, nos encontramos ante un caso de culpa consciente; y al revés, cuando ni siquiera pasó pro su mente la imagen de lo que podría ocurrir el supuesto es de culpa inconsciente o sin representación. Así planteada la diferencia, todo parece muy simple, pero en realidad la explicación abreviada esconde algunos problemas de los que nos vamos a ocupar:

La culpa consciente se ubica en una zona fronteriza con el dolo eventual, pues en ambos casos el sujeto se representa el hecho, con toda sus características incluido su efecto jurídico. Lo que cambia es la actitud: en el primer caso el sujeto confía en poder evitarlo y por eso no acepta el resultado, y se hubiese abstenido de obrar de haberlo considerado inevitable. En el segundo el agente, aunque no quiere de modo directo el hecho, asiente a su producción eventual. En definitiva lo admite, ratifica y asume, mostrando de esa manera una actitud de menosprecio hacia las normas que ordenan una conducta distinta. Dudar y no obstante obrar, equivale a obrar de todas maneras. Cosa distinta ocurre con quien no duda: está seguro de poder de evitar el perjuicio, aunque se equivoca en el empeño. Naturalmente los dos comportamientos son reprochables, pero de manera distinta. El primero con el máximo rigor correspondiente al mayor contenido el injusto del hecho: el segundo con una pena considerable menor, teniendo en cuenta la circunstancia minorante del error.

La culpa inconsciente obliga también a reflexionar sobre el arduo tema de la dirección de la acción, pues en este caso el individuo quiere emprender la acción y lo hace, aunque supone el resultado dañoso no acontecerá porque podrá evitarlo. Quiere decir que hay una acción cuya finalidad resulta indiscutible, con la única diferencia respecto del hecho doloso de la misma naturaleza que está dirigida a un objetivo distinto que aquel típicamente antijurídico que persigue quien obra con dolo. El resultado, cuyo papel en su momento veremos, no se produce por “azar”, sino por razón de la imprudencia, negligencia, etc. No hay tampoco una necesaria relación entre el hecho de representarse el resultado y que la conducta sea objetivamente lícita, pues el sujeto pudo tener consciencia de lo que podía ocurrir y no obstante actuar descuidadamente. No habría acción ilícita, entendiendo por tal asunción de riego no permitido, si el agente se representase el hecho, confiase, en evitar el resultado dañoso y obrase de manera prudente, diligente, con pericia, ect., aunque en definitiva el resultado se produzca lo mismo. Ya volveremos sobre el punto al tratar acerca de la tipicidad y la anti juridicidad.

Desde otro enfoque se puede pensar que criminológicamente considerando el caso de la culpa inconsciente es más grave, porque evidencia una total despreocupación, actitud con lo que se pueden producir resultados muy graves. El individuo que reflexiona y que se equivoca sería para tal manera de pensar - menos peligroso que aquel que obra "a tontas y a locas" sin pensar siquiera en lo que puede llegar a producir, por acción u omisión. Mencionamos las dos formas de actuar pues es notorio que la culpa consciente o con representación no es sinónimo de una conducta positiva y la culpa inconsciente o sin representación la de una actuación negativa. En ambos casos el bien jurídico resulta menoscabado, sea que el sujeto cause el daño haciendo u omitiendo. 
La culpa puede manifestarse de las siguientes maneras

\section{La imprudencia}

Es uno de los casos en que no se corresponden la representación y la realidad, o sea, un supuesto error, si es que no se trata más bien de un caso de ceguera ante los hechos. En contraposición al error en la tentativa, en que el autor imagina una realización del tipo que no se produce, el autor en la imprudencia yerra al no advertir la realización del tipo que va a tener lugar.

Es punible el comportamiento cuando los establece el StGB, si el autor no conoce todas las circunstancias pertenecientes al tipo legal, no actúa dolosamente, $16.1^{85}$, si las circunstancias son no obstante cognoscibles, actúa imprudentemente. La imprudencia es aquella forma de la evitabilidad en la que falta el conocimiento de lo que ha de evitarse. Es la falta de una relación volitiva o la falta de previsión segura.

Es una conducta positiva, consistente en una acción de la cual había de abstenerse, por ser capaz de ocasionar determinado resultado de daño o de peligro, o que ha sido realizada de manera no adecuada, haciéndose así peligrosa para el derecho ajeno, penalmente tutelado. Representa la temeridad excesiva, el ejercicio de lo que la prudencia indica no hacer o la ligereza o indebida audacia. El peligro reside en la propia conducta ${ }^{86}$.

\section{Negligencia}

Es una falta de atención, descuido que origina la culpa inconsciente, donde el autor en su falta de precaución, no ha previsto como posible el resultado criminal que ha causado. La falta de precaución ha hecho que el autor ignore o yerra acerca de la naturaleza de lo que hacía de su resultado posible. Es la omisión del autor, al obrar u

${ }^{85}$ Section 16, Mistake of fact: (1) Whosoever at the time of the commission of the offence is unaware of a fact which is a statutory element of the offence shall be deemed to lack intention. Any liability for negligence remains unaffected. (2) Whosoever at the time of commission of the offence mistakenly assumes the existence of facts which would satisfy the elements of a more lenient provision, may only be punished for the intentional commission of the offence under the more lenient provision. Ver JAKOBS, Gunter, Derecho Penal Parte General, Marcial Pons, 2da Ed., Madrid 1997, pp. 378-395.

${ }^{86}$ Ver Cuello Calón, Eugenio, Derecho Penal Parte General, Nacional, México 1968, p. 400. Donde el autor nos señala que la imprudencia supone una actividad positiva, se refiere al obrar irreflexiblemente, sin precaución ni cautela. 
omitir, de los cuidados debidos que no le permitieron tener conciencia de la peligrosidad de su conducta para la persona, bienes o intereses de terceros ${ }^{87}$.

Es conocida como la culpa sin previsión o la culpa inconsciente, el autor no se dio cuenta a raíz de su falta de cuidado, precaución o atención, no ha previsto debiendo hacerlo el verdadero carácter de su comportamiento.

\subsection{Negligencia en los Estados Unidos}

En los Estados Unidos de Norte América la negligencia recibe el nombre de negligence y se señala que es la conducta que recae bajo los estándares establecidos por la ley para la protección de otros contra peligros de riesgos no razonables ${ }^{88}$. Dentro de los elementos de la causa de acción podemos mencionar: $a$ ) el deber de cuidado ${ }^{89}$; b) el violar el deber ${ }^{90}$; c) causa próxima ${ }^{91}$; d) daños ${ }^{92}$.

Además se hace referencia al riesgo no razonable: donde el autor es requerido a reconocer que su conducta conlleva un riesgo a causar una invasión al interés de otro si un hombre razonable ${ }^{93}$ accionara de esa manera.

${ }^{87}$ Desde el punto de vista psicológico la negligencia se deriva del funcionamiento defectuoso de la memoria y de la asociación, respecto a la atención, de modo que no surjan recuerdos que la activen, imponiendo el debido comportamiento. Vendría a considerarse una forma de desatención, inercia psíquica.

${ }^{88}$ Negligence is conduct which falls bellow the standard established by law for the protection of others against unreasonable risk of harm. It does not include conduct recklessly disregardful of an interest of others.

${ }^{89}$ Duty of care: the existence of a legal duty on the part of the defendant to conform to a specific standard of conduct for the protection of the plaintiff against an unreasonable risk of harm.

${ }^{90}$ Breach of duty: a breach of that duty by the defendant's failure to conform his conduct to the required standard.

${ }^{91}$ The breach of the duty by the defendant constituted the proximate or legal cause of plaintiff's injury.

${ }^{92}$ Damages: the plaintiff has suffered actual harm to himself or his property that is measurable and compensable in Money damages.

${ }_{93}$ The reasonable person: when an act is negligent only if done without reasonable care, the care which the actor is required to exercise to avoid being negligent in the doing of the act is that which a reasonable person in his position, with his information and competence, would recognize as necessary to prevent the act from creating an unreasonable risk of harm to another.

En cuanto a la aplicación del standard podemos señalar: for the purpose of determining whether the actor shuld recognize that this conduct involves a risk, he is required to know. $a$ ) the qualities and habits of human beings and animals and the qualities, characteristics, and capcities of things and forces and forces in so far as ther are matters of commons knowlwdge at the time 


\section{Impericia}

Es la insuficiente aptitud, habilidad o deficiencia técnica, para el ejercicio de un determinado oficio, arte o profesión, que ordinariamente se exige en el desempeño de ciertas funciones y que es originante de resultados dañosos por parte de quien carece de preparación debida. La impericia supone, el ejercicio de una actividad determinada para la que se requieren los conocimientos más o menos especializados. Dentro de los presupuestos de la impericia podemos señalar la ineptitud y la inhabilidad y como fuente de estos la ignorancia o el error.

\section{Tipo objetivo: La acción típica, deber de cuidado el resultado}

\subsection{Acción Típica}

Los tipos penales en nuestro Código Penal han sido redactados como dolosos, es decir, se presume el dolo en cada unos de ellos pero, como excepción aparece los tipos culposos, los cuales solo se sancionan conforme al artículo 12 de nuestro ordenamiento legal. ${ }^{94}$

and in the community; and $b$ ) the common law, legislative enactments, and general customas in so far as they are likely to affect the conduct of the other or third persons.

En cuanto a los grados de neglignecia podemos señalar: recklessness: the actor's conduct is in reckless disregard of the safety of anoter if he does an dact or intentionally fails to do an act which it is duty to the other to do, knowing or having reason to know of facts which lead a reasonable man to realize, not only that his conduct creates an unreasonable risk of physical harm to another, but also that such risk is substantially greater than that which is necessary to make his conduct negligent.

En cuanto a la prueba de la neglingencia por parte de la function de la corte y de los jurados: $a$ ) en la acción por negligencia la corte determina: $a$ ) whether the evidence as to the facts makes an issue upon which the jury may reasonably find the existence or non existence of such facts: $b$ ) whether such facts give rise to any legal duty on the part of the defendant; $c$ ) the standard of conduct required of the defendant by his legal duty; $d$ ) whether the defendant has conformed to that standard, in any case in which

${ }^{94}$ Hurtado Pozo, José, Manual del Derecho Penal Parte General I, Editora GRIJLEY E.I.R.L. 2005, p 717, señala "Los delitos culposos pueden ser de comisión y de omisión, así como de pura actividad o de resultado. Estos últimos son los que con mayor frecuencia se han previsto en la Ley. En cuanto a los primeros, basta la realización del comportamiento, y por lo tanto, no hay que comprobar la existencia de un resultado (daños o puesta en peligro concreto de 
Los tipos culposos no son determinados legalmente, en el sentido de que no tenemos una definición exacta de lo que se debe entender por culpa, es un tipo abierto. En términos generales podemos decir, actúa culposamente el que no observa cuidado requerido, en otros términos, el que no cumple con el deber objetivo de cuidado el encargado de cerrar el tipo es el Juez y no el legislador que dio la ley, en otras palabras, es el órgano Administrador de Justicia y no el Poder Legislativo el que da contenido al tipo, por lo que se puede estar afectando el principio de legalidad.

\section{El Deber Objetivo de Cuidado}

El deber de cuidado es un deber objetivo, ya si cada persona fuese libre de atenerse a lo que personalmente le fuere posible se ocasionaría el caos, y amenazando desde luego la vulneración de los bienes jurídicos.

El deber objetivos, se debe valorar la conducta realizada por el sujeto desde el punto de vista de un observador imparcial, debemos tener en cuenta el cuidado objetivo y el normativo o valorativo; es objetivo cuando el sujeto actuó en el caso concreto con el cuidado requerido por la sociedad hombre medio; es normativo o valorativo cuando el comportamiento realizado se adecua a lo establecido por la sociedad, es decir, se compara lo realizado por el sujeto y lo que hubiese hecho el hombre medio para ver si coincide: de coincidir no se puede castigar porque cualquiera hubiese reaccionado de la misma manera, si actuó con una diligencia menor, este es culposo. ${ }^{95}$

un bien jurídico). El carácter culposo de la comercialización o tráfico de productos nocivos a la salud de las personas no está, en buen medida, en relación con el mismo acto de poner en venta o en circulación, importar o tomar en depósito (comportamientos siempre intencionales), sino con el hecho de que el consumo, empleo normal o probable del producto pueda comprometer la salud de las personas.

Tratándose de delitos de resultado, el agente debe, mediante su comportamiento, producir la modificación del mundo exterior previsto en el tipo legal. El juicio de valor negativo referente a la producción del perjuicio prohibido (muerte o lesiones de una persona, por ejemplo) constituye, junto al juicio negativo sobre la acción de crear o aumentar un peligro, un aspecto esencial de la tipicidad del delito culposo. Por esto, dicho resultado es un elemento constitutivo del tipo legal y no solo una condición objetiva de punibilidad. El criterio contrario no puede ser justificado afirmando que solo se pueden prohibir acciones y no resultados. Tampoco es decisivo que la represión del autor de un comportamiento culposo donde de la materialización aleatoria del peligro creado o aumentado mediante dicho comportamiento.

Para determinar la relación de causalidad deben aplicarse los mismos criterios empleados con relación a los delitos dolosos. Así mismo, se aplicarán los criterios referentes a la imputación objetiva. Al respecto no hay que olvidar, por un lado, que tanto en la jurisprudencia y en la doctrina comparada se ha invocado con frecuencia la denominada causalidad adecuada y, por otro, que este criterio se e3ncuentra en la base de la concepción de la imputación objetiva.

${ }^{95}$ PeÑa CABRERA, Raúl, Tratado del Derecho Penal, Editora Jurídica Grijley, 5ta edición 1994, pp, 464, establece La lesión del deber objetivo de cuidado, constituye el primer momento 


\section{El Resultado}

Entre la acción y el resultado, se presenta la relación de causalidad, la que en los delitos culposos gira sobre la teoría de la equivalencia de condiciones toda causa es condición de un resultado, a esto se debe añadir el criterio de la imputación objetiva, la producción del resultado se da por la inobservancia del deber objetivo de cuidado, el cual debe poderse imputar objetivamente al mismo. Resulta un requisito indispensable para la configuración de este tipo de delitos, el que se dé una concreta afección al bien jurídico, no existiendo en ningún caso una tentativa culposa. ${ }^{96}$

en el proceso de subsanación de la conducta del agente dentro del tipo de injusto culposo. La acción generalmente lícita desplegada por el autor, debe verificarse contraviniendo la normal precaución que le son exigidas. Estos supone que el agente debió prever lo que una persona con diligencia normal hubiera previsto en su caso, respecto a que la acción que realizaba incrementaba el riego de provocar una afección a un bien jurídico (previsibilidad objetiva) v.gr., el sujeto que mata a otro, en circunstancias en que limpia el arma de fuego, debía de prever la potencialidad dañosa de ésta. Esto no significa que se prescinda del examen de la conducta del autor, en vista a sus condiciones personales, entendido como "poder concreto de evitación". La adecuación a la conducta homicida requiere de un juicio normativo, que surge de la comparación entre la conducta que hubiere adoptado un hombre prudente razonable en la situación del autor y la observada realmente.

En el caso de actividades de utilidad social imprescindible (operaciones quirúrgicas, tránsito vehicular, empleo de maquinarias peligrosas, etc) que lleva implícita un mayor peligro para la vida, la determinación de falta de cuidado externo deberá hacerla el juzgador teniendo en consideración los niveles "riegos permitido" que presenta.

El deber objetivo de cuidado tiene en algunos casos, plasmación en un conjunto de reglas especiales de carácter administrativo (regla de tránsito, de seguridad laboral o la llamada lex artis). Su violación constituye una condición necesaria, pero insuficiente para establecer la responsabilidad por culpa del infractor. Hay casos en que la observancia puede ser imprudente y la inobservancia prudente; el invadir el lado izquierdo de la calzada, cuando no viene nadie en contra, para evitar atropellar a un niño, es, a pesar de la infracción formal un acto prudente, el seguir por el mismo lateral puede ser imprudente.

Por último, la determinación del cuidado observador por el autor en aquellas actividades que requieren el concurso de otras personas (tránsito vehicular, construcción de edificios, operación quirúrgica, etc.,), se hará teniendo en cuenta que a cada participante le es admisible confiar en que el otro partícipe desarrollará parte de la actividad de la manera correcta, salvo que las circunstancias especiales del caso hagan reconocible lo contrario, por ejemplo: el cirujano debe confiar en la enfermera le asista correctamente, de tal manera que si ésta equivoca la inyección, no es la acción de aquél sino la de ella la que lesiona el deber objetivo de cuidado.

${ }^{96}$ Altavilla, Enrico, La Culpa Del Delito Culposo, sus Repercusiones Civiles, su Análisis Psicológico, Editorial Temis S.A., Santa Fe de Bogotá - Colombia, 1999, p.140, establece, La conducta humana es una manifestación extrínseca de la personalidad, que ocasionado en el mundo exterior, con la coeficiencia de factores externos (exógenos), una modificación que los filósofos llaman acontecimientos y los juristas resultado.

Podemos afirmar que, a impedir o a producir la realización del resultado, se dirigen los preceptos penales que prohíben o imponen conductas con capacidad para ocasionarlo. 
La producción del resultado no es una condición objetiva de punibilidad, no basta con que se produzca, éste debe ser imputado al autor de la falta al deber objetivo de cuidado, debe existir una determinada relación entre éste y el resultado, debido al riesgo que se ha creado o aumentado. ${ }^{97}$

\section{El tipo Subjetivo}

Posibilitar de conocer el peligro que la conducta ocasiona para los bienes jurídicos, previsibilidad y deber de evitar el resultado dañoso. ${ }^{98}$

El resultado puede ser de daño o de peligro, según el cambio deseado se realice (como la muerte de un hombre), o se hayan puesto en movimiento fuerzas causales capaces de producirlo, pero sin producirlo (como el choque de un tren en una vía obstruida, sin que resulten daños).

Se discute si el resultado del peligro basta para integrar los delitos culposos. Rocco, sostuvo la opinión negativa: "los delitos del peligro nunca podrán ser delitos culposos. En efecto, la conducta que contenga en si misma, no un peligro efectivo, sino la posibilidad de un peligro, tendrá por resultado por un peligro efectivo, no un daño efectivo, y por lo tanto no podrá originar la noción de la culpa y del delito culposo”.

${ }^{97}$ Peña CABrera, Raúl, Tratado del Derecho Penal, Editora Jurídica Grijley, 5ta edición 1994, p. señala. El hecho de que se exija necesariamente la causación de un resultado, en modo alguno significa que sea el fundamente del injusto. En el Perú se castiga la imprudencia cuando se ha seguido un resultado, cumpliendo con principio de intervención mínima; de modo, cuando no se haya generado consecuencias, podría tratarse de una infracción administrativa, por ejemplo, e exceso de velocidad.

Lo que importa es que el resultado se derive casualmente de la acción de agente. Esto es algo indiscutible, pero como ya lo dijimos en su oportunidad, en los delitos dolosos la imputación del resultado deberá solventarse "normativamente", razón por la cual se hicieron las observaciones pertinentes a las teorías de la causalidad.

${ }^{98}$ HuRTAdo Pozo, José, Manual del Derecho Penal, Editora Jurídica Grijley 2005, p. 276, En la medida en que se procede al análisis de todos los aspectos subjetivos del comportamiento en el nivel de la culpabilidad (orden de tener cuidado y prever el perjuicio respecto a la persona del autor), se niega la existencia o, al menos, la necesidad práctica de considerar la presencia de un tipo legal subjetivo en los delitos imprudentes. De modo que se considera dado el injusto en estos delitos en razón a tres factores: La posibilidad de prevenir el riesgo de la realización del hecho típico, el obrar sin cuidado exigido del modo objetivo y, en caso necesario, la realización del resultado típico por la violación del deber de cuidado. El reproche de culpabilidad tendría como objeto la actitud ante el derecho. Si el suceso es imprevisible, se trata de un caso fortuito, el mismo que esta fuera del derecho penal.

Se si tiene en cuenta la delimitación hecha entre culpa con representación (consciente) y culpa sin representación (inconsciente), hay que preguntarse si ello no implica matizar la afirmación de que no es posible concebir el tipo subjetivo en los delitos culposos. Tratándose de la culpa sin la representación, resulta imposible hacerlo por que el agente no se ha representado los presupuestos del tipo objetivo. Respecto a los ejemplos dados, es lo que sucede cuando el chofer ni siquiera perciba la luz roja del semáforo y el ama de casa olvida apagar la cocina. Por el 
Se debe analizar cuál es la relación concreta que existe entre el sujeto y el proceso que ha desencadenado. Examinando la conciencia del individuo respecto del proceso que se ha dado nos llevará a una graduación de la culpa, es aquí donde cobra importancia la diferencia que se ha señalado anteriormente entre culpa consciente, con representación, e inconsciente, sin representación.

En este punto donde se pueden dar cruces entre la culpa consciente y el dolo eventual; en el primero existe una actitud de confianza dada por las circunstancias, en el segundo, el sujeto cuenta con el suceso para afectar el bien jurídico.

En ciertos casos se debe ver si el sujeto tiene un conocimiento especial sobre las circunstancias, el cual lo hace responsable de su actuar. Un ejemplo claro de esto se presenta en el caso del médico que somete a su paciente a una operación, y el paciente muere; esto, aunque sea previsible no sea suficiente, se debe ver si el médico actuó cumpliendo todas las reglas de conducta que le impone realizar una operación.

Para que el sujeto responda a título de culpa, le debe haber sido previsible que actuando de tal manera pudiera afectar al bien jurídico, esto debe ser complementado por el hecho de que el sujeto debe haber tenido en sus manos el evitar el daño causado si hubiese actuado con mayor diligencia.

\section{Fundamentación jurídica de la culpa}

Así como el dolo es una volición delictiva. Y partiendo desde una política criminal, se considera el desvalor del resultado, cuyo fundamento es la afectación del bien jurídico y por consiguiente la imputación objetiva, que consiste en atender cuáles son los fundamentos o argumentos que permiten sostener que la afectación al bien jurídico es obra del autor.

La previsibilidad condiciona el deber de cuidado, quien no puede prever no tiene a su cargo el deber de cuidado y no puede violarlo. El deber de cuidado, cuya violación hace incurrir en culpa, tiene sus riesgos creados o afrontados fuera del desenvolvimiento permitido de la vida individual o social; así la vida práctica con sus exigencias, impone una serie de actividades que en sí mismas no pueden realizarse sin riesgos para la persona y bienes de terceros, como son, el tránsito de los vehículos, las actividades industriales, la

contrario, tratándose de la culpa con representación, el agente deber ser consciente de todas las circunstancias que hacen de su acción un comportamiento peligroso no permitido. De esta manera, él se representa la posibilidad de lesionar el bien jurídico protegido; es decir, es consciente de las circunstancias previstas en el tipo legal objetivo. En esto reside, en efecto, su semejanza con el dolo eventual. En este último, la decisión con que actúa el agente respecto al resultado permite decir que lo acepta, lo asume, lo hace suyo; mientras que el agente culposo confió en que no se produzca. 
actividad de los médicos y las deportivas, etc. La previsión de estos riesgos se hallan implícitamente permitidos al aceptarse la licitud de las actividades que los llevan inherentes en su normal ejercicio.

\section{DELITOS CULPOSOS}

\section{BIBLIOGRAFÍA}

Zaffaroni, Tratado de Derecho Penal Parte General, Ediar, Argentina 1999; Villa Stein, Javier, Derecho Penal parte General, Grijley 2008; Antonio TerRaGni, Marco, El Delito Culposo, Editorial Rubinzal -Culzoni - Chile, 3573; VILLAVICENCIO Terreros, Felipe, Derecho Penal Parte General, Grijley, Lima 2007; Hurtado Pozo, José, Manual del Derecho Penal, Parte General I, Editora Jurídica Grijley E.I.R.L. Perú. 3 Edición 2005; Mantovani, Ferrando, Diritto Penale, Cedam, Milano 2001; Jimenez DE AzuA, Tratado de Derecho Penal, T. V, Losada, Buenos Aires 1963; JAKOBS, Gunter, Derecho Penal Parte General, Marcial Pons, 2da Ed., Madrid 1997; Cuello Calón, Eugenio, Derecho Penal Parte General, Nacional, México 1968; PeÑa CABRERA, Raúl, Tratado del Derecho Penal, Editora Jurídica Grijley, 5ta edición 1994; Altavilla, Enrico, La Culpa Del Delito Culposo, sus Repercusiones Civiles, su Análisis Psicológico, Editorial Temis S.A., Santa Fe de Bogotá - Colombia, 1999 